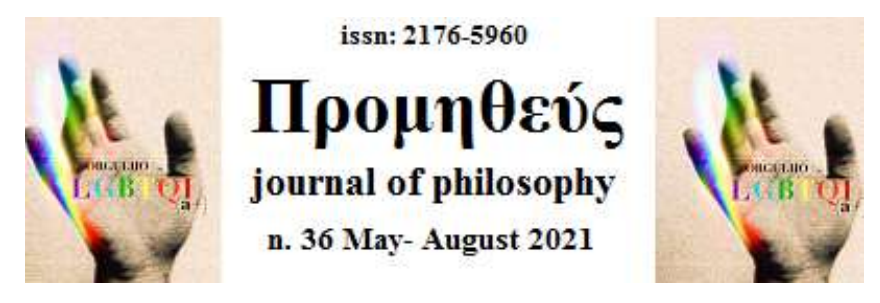

\title{
Considerações iniciais sobre Laozi e o Dao De Jing e a sua relação com o estoicismo de Epicteto ${ }^{1}$
}

\author{
André Capistrano Gama Santana ${ }^{2}$
}

\begin{abstract}
Resumo: o presente artigo tem dois objetivos: o primeiro consiste em apresentar, mesmo que em linhas gerais, o pensamento expresso na obra de Laozi, Dao De Jing, considerado um dos maiores clássicos do pensamento chinês. $O$ segundo objetivo é travar um diálogo inicial entre pressupostos apresentados pelo daoismo de Laozi e pelo estoicismo de Epicteto e, a partir daí, estabelecer espaços de discursão entre as duas tradições de pensamento.
\end{abstract}

PALAVRAS-CHAVE: Laozi, Epicteto, Daoismo, Estoicismo.

Abstract: The present article has two goals: the first is to present, even if in general lines, the thought expressed in Laozi's work, Dao De Jing, considered one of the greatest classics of the chinese thought. The second goal is to engage in a initial dialogue between the assumptions presented by Laozi's daoism and Epictetus's stoicism and, from here, establish a discursive space between these two traditions of thought.

KEYWORDS: Laozi, Epicteto, Daoism, Stoicism.

\footnotetext{
${ }^{1}$ Trata-se de um texto modificado da apresentação "Considerações Iniciais sobre Laozi e o Dao De Jing" feita no I Seminário do GT Epicteto.

${ }^{2}$ Mestrando do Programa de Pós Graduação em Metafísica da Universidade de Brasília (PPGM-Unb). https://orcid.org/0000-0003-2379-3704
} 


\section{Introdução}

De acordo com Pierre Hadot, no livro intitulado Philosophy as a Way of Life, a filosofia, entre as suas diversas funções, tem como papel colocar-se como proposta de vida para o seu adepto. Segundo a leitura hadotiana, é na filosofia antiga, sendo mais evidente no período helenístico, que essa possibilidade de abordagem filosófica, cuja característica mais fundamental é a união entre o discurso e a prática, transformando a filosofia em uma espécie de "palavra viva", adquire maior destaque.

É nesse cenário que se insere o estoicismo e, portanto, Epicteto, um dos mais importantes representantes do estoicismo imperial. Epicteto, como muitos outros filósofos antigos, não escreveu nada, mas os seus ensinamentos foram registrados por Lúcio Flávio Arriano Xenofonte, ou apenas Arriano.

Arriano galgou cargos importantes durante do reinado de Adriano, por volta do século II d.C., alcançando o posto de legado da Capadócia, por volta de 130 e 131. É sabido que Arriano escreveu muitas obras de história, mas, como observa Aldo Dinucci (2020, p. 31), com exceção de Anábase de Alexandre, que chegou completa até os dias de hoje, a maioria dos seus escritos foram destruídos ou chegaram incompletos até nós. É nesse contexto que tanto o Manual de Epicteto, ou Encherídion, quanto as Diatribes, ou Discursos, se enquadram.

A filosofia de Epicteto, como observa John Sellars (2006, p.34-35), tem uma função terapêutica, isto é, ela deveria exercer um papel de cura das doenças da alma. É por isso que o estoicismo epictetiano tem como característica marcante levar o seu adepto a lidar, a partir de sua capacidade de escolha (prohairesis), de forma saudável e equilibrada com os seus desejos e aversões, suscitados pelo assentimento dado às impressões (phantasia). É pela busca da impertubabilidade da alma, sendo construída por meio do desenvolvimento de uma postura equânime diante das situações que se colocam diante do homem, que o modelo ideal da ação humana, representado na figura do sábio, é construído dentro do estoicismo.

Expandindo a proposta de Hadot para além do escopo da filosofia grega, encontramos outras tradições de pensamento que pretendem se colocar, também, como 
propostas de vida, aliando discurso e prática. Nesse sentido, vamos nos deter, nesse artigo, em uma análise sobre as impressões iniciais da leitura do Dao De Jing, obra de Laozi que inaugura a escola de pensamento daoista, e, a partir daí apresentar uma proposta de diálogo entre o estoicismo e o daoismo utilizando a construção do arquétipo do sábio como um solo comum entre essas duas tradições de pensamento. Com esse intento, vamos iniciar a nossa discussão com uma breve contextualização histórica do daoismo e de Laozi para, em seguida, apresentar alguns de seus temas mais importantes e, por fim, delinear o processo de estruturação do sábio estoico em relação ao shengren (圣人), ou o sábio daoista.

\section{Breve contextualização histórica de Laozi e do Dao De Jing}

De acordo com Wing-Tsit Chan (1963a, p. 136), a civilização chinesa teria sido completamente diferente se a figura de Laozi, e a sua obra, não tivessem existido. O daoismo, proposta filosófica inaugurada por Laozi com o Dao De Jing (道德经), traduzido como Clássico do Caminho e da Virtude, foi fundamental para moldar uma cultura milenar. Sem a obra de Laozi, talvez o budismo, por exemplo, importado da Índia a partir das trocas culturais proporcionadas pelo estabelecimento de rotas comerciais asiáticas, não tivesse se desenvolvido como uma tradição independente de sua contraparte indiana e se estruturado como a tradição Chan, ou Zen, quando foi exportada posteriormente ao Japão. Mesmo o confucionismo, doutrina de pensamento dominante durante o período em que o termo "escola daoista" é pela primeira vez mencionando, por volta do século I a.C. (CHAN, 1963a, p. 136), dialogou e sofreu influência dos ensinamentos expressos no Dao De Jing. Diante disso, se temos a pretensão de compreender a dimensão do impacto da filosofia daoista na China, precisamos antes contextualizar historicamente a obra de Laozi e investigar alguns dos pressupostos filosóficos apresentados no Dao De Jing.

De acordo Eva Wong (1997, p.23) a maioria dos historiadores concorda que a obra de Laozi situa-se no chamado período das Primaveras e dos Outonos, entre os séculos VIII e V a.C., aproximadamente, ocasião de muita turbulência interna com o conflito entre as várias potências políticas e militares presentes no território chinês. Nesse período, Chan (1963b, p.4) afirma que ao contrário das tradições filosóficas gregas ou indianas, que se dedicavam à especulação sobre a Natureza ou à 
contemplação do espírito, a filosofia chinesa surge como resultado da percepção da degradação política e social de seu próprio tempo. Assim, seja o daoismo, o confucionismo ou o legalismo, por exemplo, todas essas escolas de pensamento tinham como objetivo comum oferecer respostas a um cenário de crise na história política, social e filosófica da China.

Quando se trata de uma obra clássica, um dos primeiros questionamentos que podemos fazer diz respeito ao seu autor. Nesse sentido, precisamos destacar que Laozi é muito mais um epíteto que um nome próprio. Esse termo significa "velho mestre" e isso, por si só, já indica a importância dessa figura no pensamento chinês, uma vez que a imagem do velho mestre envolve até mesmo lendas e disputas historiográficas sobre um suposto encontro de Confúcio com Laozi, em que o primeiro solicitou informações sobre rituais e cerimonias ao último.

As teorias sobre a existência e a identidade de Laozi levantam problemas sobre a própria autoria do seu livro. Se, por um lado, encontramos aqueles que sustentam a existência de uma figura histórica única que seria o Laozi, por outro lado, encontramos também defensores da hipótese de que o nome de Laozi representa um conjunto de autores, ou, pelo menos, de organizadores, que adotaram o personagem do velho mestre para dar coesão à construção do Dao De Jing.

De acordo com Chan (1963b, p. 73), um dos argumentos favoráveis à teoria do autor único destaca que as recorrentes referências ao pronome "eu", no texto de Laozi, evidenciam a presença do próprio autor no texto, como podemos perceber em alguns trechos do Dao De Jing, logo abaixo:

"Por que estimar minhas próprias aflições?

Tenho aflições por estimar a mim mesmo.

Sem isso, por que teria aflições? (LAOZI, 2017, p.33)

\footnotetext{
"Todos possuem em excesso.

Só eu vagueio solitário como um errante!

Ó meu coração estúpido e confuso

Todos são ofuscantes.

Só eu sou turvo.” (LAOZI, 2017, p.51)
} 
Já a teoria dos vários autores/organizadores, segundo Chan (1963b p.72), defende, entre outras possibilidades, que, considerando o período histórico em que o Dao De Jing foi escrito, não haveria, naquela época, uma tradição cultural chinesa de produção autoral de livros, uma vez que a escrita tinha fins meramente administrativos na manutenção da burocracia chinesa. Michael LaFargue (1992, p.196), levanta outra hipótese: para ele, o Dao De Jing é, tradicionalmente, composto por 81 capítulos, entretanto, não há nenhuma evidência de que os arranjos desses capítulos sejam originais. LaFargue diz que muitos dos capítulos dessa obra poderiam ser lidos sozinhos ou dão a impressão de uma descontinuidade temática em trechos do livro, o que leva a crer que a hipótese Dao De Jing ser um compilado de ensinamentos composto por mais de um autor é uma possibilidade aceitável de ser discutida.

\section{Alguns temas do Dao De Jing}

O Dao De Jing, como já observamos, é uma obra que tenta apresentar soluções para os problemas de sua época e, nesse sentido, ela dialoga criticamente com outras perspectivas filosóficas, sendo a principal delas o confucionismo. De acordo com Chan (1963a, p. 136) entre os vários pontos em que Laozi e Confúcio se distanciam podemos destacar o modo de agir no mundo. O conceito mais fundamental do pensamento confuciano é definido pelo ideograma chamado rén (仁), traduzido como benevolência ou humanidade. A partir da noção de rén, Confúcio constrói uma filosofia estruturada na manutenção de uma ordem social harmônica, norteada por uma série de ritos, cerimônias e deveres comunitários.

$\mathrm{Na}$ antípoda da perspectiva confuciana, situa-se Laozi. A filosofia daoista enfatiza o desenvolvimento individual do seu adepto, a tranquilidade da mente e a paz de espírito. Devemos entender que enquanto Confúcio ressalta a importância da adequação social a uma regra harmoniosa e defende o estudo das normas e a ação do homem no ambiente em que ele habita, Laozi, por outro lado, critica a ortodoxia da sociedade chinesa, a artificialidade das normas e preconiza o wuwei (无为), ou a nãoação. É pertinente destacar que a não-ação não dever ser confundida com inação. Pela não-ação, Laozi busca estabelecer um modo pelo qual o homem sábio possa atuar no mundo em acordo com o Dao, ou seja, trata-se de uma ação natural, tal qual como a imagem do rio que banha as suas margens sem, no entanto, apegar-se a elas. O conceito 
de wuwei é fundamental para o pensamento de Laozi e essa importância é notada com a sua apresentação já no segundo capítulo do seu livro em que é dito o seguinte:

\author{
"Por isso, o sábio age através da Não Ação \\ e pratica o ensinamento sem falar. \\ Assim, todos os seres atuam sem nenhuma intervenção, \\ geram sem se apoderar e realizam sem depender. \\ Cumprida a obra, o sábio não se apega. \\ Não havendo apego, nada se perde.” (LAOZI, 2017, p.11)
}

A relação da não-ação (wuwei) com o Dao é reforçada no decorrer de todo o Dao De Jing, como podemos observar, por exemplo, no capítulo 37, em que Laozi diz que "O Dao é a Constante Não Ação [...]”. Nesse ponto, podemos nos perguntar sobre o significado da palavra "Dao" e qual a sua importância na filosofia chinesa.

O ideograma Dao (道) é polissêmico e tem sido utilizado para representar ideias como as de "caminho", "estrada", "algo que se dirige a algum lugar", "método", "princípio", "verdade" e, finalmente, "realidade". Esse ideograma permeia todas as escolas de pensamento da China antiga, entretanto, como destaca Chan (1963b, p.03-06), foi com Laozi que o conceito de Dao ultrapassou a sua tradicional compreensão no campo ético e social, como encontramos, por exemplo, em Confúcio ou Mozi, e passou a assumir, pela primeira vez, uma dimensão metafísica.

O Dao, para Laozi, é concebido como a fonte originária de tudo o que existe e que tudo compreende sem ser compreendido por nada. Como observa Livia Kohn (2008, p.20), o Dao também é entendido como a ordem natural do universo, sendo expresso pelas mudanças rítmicas e processos padronizados da natureza, como, por exemplo, a passagem das quatro estações, a transição do dia para a noite e o surgimento da vida e da morte. Por isso, para os daoistas, seguir o caminho do Dao é estar em acordo com a própria natureza ou, como diz Laozi, devemos agir com naturalizade (ziran 自然).

Devemos ter em mente que, apesar do Dao ser o princípio sob o qual tudo é originado, ele não deve ser entendido como uma espécie de divindade ou de espírito absoluto. Fabrizio Pregadio (2008, p.304), em sua enciclopédia, diz que o Dao dos 
daoistas de forma alguma corresponde à ideia de Absoluto presente em sistemas filosóficos ou religiosos orientais ou ocidentais. A advertência contra a reificação do seu conceito mais fundamental é apresentada já nas duas primeiras frases do Dao De Jing quando, tentando definir o que é o Dao, Laozi (2017, p.09) diz: "O Dao que se pode falar não é o Dao Constante. O nome que se pode nomear não é o Nome Constante”.

Essa resistência à definição é justificada pela conotação negativa que o ato de nomear (ming 名) adquire no pensamento daoista, pois como comenta Wang Bi (2003, p.121), nomear refere-se a um processo que pode ser demonstrado, que possui uma forma, e se o Dao fosse demonstrável ou definível ele se tornaria um fenômeno particular, ou seja, não poderia mais ser eterno, natural, e capaz de abarcar a complexidade dos demais fenômenos. Giorgio Sinedino (2016, p.13) afirma que atribuir nomes às coisas tinha um papel de sacralidade no pensamento chinês e esse ato unificava a dimensão do sagrado à da política, pois narrativas tradicionais, na história chinesa, atribuíam aos "reis sábios" o papel civilizador do seu povo que seria feito a partir da atribuição dos nomes às coisas, pois é a partir da designação do seu nome que um objeto teria a sua utilidade adquirida no mundo. Nesse contexto proposto por Sinedino, e considerando teor crítico que Laozi busca empreender às correntes políticas de sua época, nomear seria tentar conter a "essência" do Dao dentro de normas artificiais por meio da criação de conceitos e isso contrariaria um dos aspectos mais fundamentais do Dao de Laozi, ou seja, a sua naturalidade.

O Dao, entendido como o princípio originário, assume em Laozi um caráter único. Ele abarca, dentro de sua totalidade, tanto a transcendência quanto a imanência. Assim, Laozi nos diz que o Dao é ao mesmo tempo Vazio, representando o seu estado transcendente e do não-ser, e Existência, destacando a sua parte imanente cuja ação sustenta a origem de todos os seres no universo.

Ainda sobre a relação entre Vazio e Existência, Laozi inova o pensamento chinês ao afirmar que o Vazio gera a Existência, ou seja, que a existência do ser tem o seu surgimento a partir do não ser. Isso pode ser ilustrado por um trecho do capítulo 40 do Dao De Jing em que é dito o seguinte: "Todos os seres emergem da Existência. A Existência nasce do Vazio.”. 
O Vazio para Laozi não deve ser confundido como um mero espaço cuja vacuidade se dá pela falta de predicados, pelo contrário, no Dao De Jing, o Vazio é concebido como uma fonte inesgotável de criatividade, isto é, a vacuidade adquire aqui uma interpretação positiva, pois é justamente por não conter nada, isto é, por constituirse como o não-ser, é que o Vazio pode abarcar tudo tornando-se assim uma potência vital infinita e ilimitada. Wing-Tsit Chan (1963b, p.08) destaca que a compreensão do não-ser, em Laozi, é absolutamente nova é radical no pensamento chinês. Ele diz que enquanto as demais escolas de pensamento chinesas concebiam o não-ser como a falta de alguma coisa, Laozi não só deu um caráter positivo a esse conceito como também o transformou em um princípio básico de sua filosofia. Segundo Homer Dubs (apud Chan 1963b, p.08) a proposta de solução para o problema da criação do mundo a partir do não-ser, apresentada por Laozi, é nova até mesmo para o pensamento ocidental, pois o que temos aqui é a apresentação da perspectiva de um universo surgindo a partir do nada em que a não-existência não assume um caráter negativo ou de ausência. Dubs (apud Chan 1963b, p.08) complementa dizendo que, com o daoismo, podemos observar um sistema metafísico completamente diferente de qualquer proposta surgida no Ocidente porque ele não se inicia a partir de uma perspectiva materialista ou idealista, mas sim por um tripé formado por uma lei natural (o Dao), pela não existência e, por fim, pela existência, categorias fundamentais para a construção da noção de realidade para os daoistas.

Apesar de existir um longo debate entre a questão da precedência ontológica do Vazio sobre a Existência, como observa Giogio Sinedino (2016, p.15-16), esses dois atributos do Dao atuam harmoniosamente um sobre o outro como podemos ler no capítulo 11 do Dao De Jing, onde é dito que "[...] a Existência gera o proveitoso e o Vazio produz a eficácia.”. Aqui entendemos a necessidade da relação entre essas duas dimensões do Dao, mas, nesse trecho, Laozi também abre caminho para a interpretação do outro conceito que forma o título de sua obra, a saber, a virtude, ou o de (德).

Sidendino (216, p.289-90), em sua tradução do Dao De Jing, com os comentários de Heshang Gong, faz uma extensa nota sobre o tema da virtude em Laozi. Nela, Sinedino explica que, no chinês, a virtude é compreendida um tipo de índole que se obtém. Ele complementa, discutindo a história das ideias na China, que o conceito de virtude foi sendo construído cada vez mais atrelado à noção de "aprendizado" ou 
"estudo" das escolas que se formaram em torno dos primeiros mestres, ou homens sábios dentro da cultura chinesa, dentre eles estão Confúcio, Laozi e Mozi. É nesse período, diz Sinedino, que Laozi inicia a discussão sobre a distinção entre uma Virtude acima de suas variedades, como humanidade, amor universal, senso de dever etc. Sinedino complementa dizendo a Virtude de Laozi mantém o paralelismo com a ideia transcendente do Dao, o que parece ser também mais uma inovação do daoismo.

Wing-Tsit Chan (1963b, p.11-13) afirma que, em Laozi, a Virtude (德) é entendida como aquilo que o Dao manifesta em cada coisa existente do universo. Assim, se entendemos que o Dao está presente em tudo, a Virtude passa a ser percebida a partir do que cada coisa que existe no mundo obtém da manifestação do Dao, ou seja, o De, ou a Virtude, é o princípio individualizante de cada fenômeno que surge no mundo e que tem como sua fonte geradora o próprio Dao. Outra forma de entender a relação entre o Dao e o De é pensar no Dao como sendo uma força criativa que faz um fenômeno se manifestar e o De é a condição para a manutenção desse fenômeno no mundo. Podemos ilustrar essa interpretação com um trecho do capítulo 51 do Dao De Jing em que Laozi diz:

\footnotetext{
O Dao gera, a Virtude cultiva, a matéria forma e as condições realizam.

Todos respeitam o Dao e estimam a Virtude.

O Dao é respeitável e a Virtude é estimada por não intervirem na Constância Natural.

Por isso, o Dao gera, a Virtude cultiva

e ambos concedem crescimento e nutrição, desenvolvimento e maturação, sustento e proteção. (LAOZI, 2017, p.127) [51]
}

No Dao De Jing, Laozi também prevê o cultivo da virtude pelos homens. Essa possibilidade pode estar relacionada ao projeto político e ético defendido pelo pensador chinês à sua época. Não são poucas as menções à figura do homem sábio, figura essa que deveria ser encarnada pelos reis ou nobres que governariam um povo. Contudo, não podemos deixar de destacar que a leitura dessa obra se esgota apenas pela via política e ética. O Dao De Jing também abre espaço para interpretações existenciais, religiosas e 
místicas, uma vez que conceitos como os de não-ação, humildade, a moderação dos desejos e o cultivo interno pela meditação, da forma como são apresentados por Laozi, apresentam um alto grau de complexidade hermenêutica.

O Dao De Jing é um livro que pode ser interpretado sob vários enfoques. Lívia Khon (2008, p.24) diz que essa obra pode ser lida como um texto religioso, político, ético, militar, como um tratado naturalista ou um livro que lida com questões psicológicas e sociais, por exemplo. Ela defende que mesmo se o leitor decidir abordar um enfoque particular ele será tomada por uma série de contradições, pois o Dao De Jing é uma obra que se estrutura pela rejeição de julgamentos de valor ou pelo abandono da escolha por um dos membros dos pares de polaridades que ela apresenta em seu texto (como a transcendência e a imanência, o Vazio e o Existência etc.). O Dao De Jing é uma obra que busca se articular pela complementaridade dos opostos e é essa característica caleidoscópica da obra de Laozi que a torna tão importante tanto do ponto de vista das tradições de pensamento ocidentais quanto orientais.

\section{O sábio estoico e o shengren (圣人)}

Se, entre as mais variadas formas de se interpretar o papel da filosofia na história, enveredarmos pela perspectiva proposta por Pierre Hadot de filosofia como modo de vida, então, encontramos um campo fértil para o diálogo entre o daoismo e o estoicismo que se constrói, principalmente, como trajetos possíveis para uma vida rumo à conquista de uma cosmovisão única, chamada por eles de sabedoria.

A figura do sábio ou, em chinês, shengren (圣人), é um tema recorrente não só no pensamento de Laozi, mas também na filosofia estoica e, portanto, na obra de Epicteto. É por meio da construção dessa imagem arquetípica do sábio, o sujeito que adquire uma cosmovisão idiossincrática e destaca-se do vulgo, que essas duas tradições de pensamento encontram espaço para um frutífero diálogo.

Para Laozi, o sábio parece ter uma importância decisiva em sua obra, pois, assim como a referência ao wuwei aprece já no segundo capítulo do Dao De Jing, como falamos anteriormente, nesse capítulo Laozi também faz destaca a figura do sábio, indicando, assim, uma relação direta entre o estado de ser sábio e a atuação pautada pela não-ação. Ele diz que “[...] o Sábio age através da Não Ação e pratica o ensinamento 
sem falar." e, também, que "Cumprida a obra, o Sábio não se apega. Não havendo apego, nada se perde". O sábio, dentro do pensamento daoista, é apresentado como o governante ideal, pois, como vemos no capítulo 03, “[...] o governo do Sábio esvazia o coração, mas sacia o ventre, enfraquece a ambição e fortalece os ossos." e, no capítulo 65:

\author{
"É difícil governar o povo \\ quando há excesso de sagacidade.
}

Assim, governar com sagacidade é usurpar o reino.

Governar sem sagacidade é prosperar o reino.

Quem conhece os dois modelos

e sempre escolhe o ideal

possui a Virtude Misteriosa.” (LAOZI, 2017, p.157)

Como destacado anteriormente, a imagem do sábio como o governante ideal não é justificativa para o Dao De Jing ser reduzido a uma leitura puramente política. $\mathrm{O}$ governo do sábio envolve, antes de sua dimensão externa, voltada para a administração política do território e o atendimento das necessidades do seu povo, um cuidado interno que implica o próprio desenvolvimento da virtude (德), cujo significado envolve a harmonização de seu modo de vida com o Dao (道) guiando suas ações a partir de sua naturalidade, ziran (自然).

Da mesma forma, a filosofia, na Antiguidade, privilegiava doutrinas de ensinamentos voltadas não só para o discurso externo, mas para o próprio modo de viver do filósofo. Essa perspectiva que une a teoria e a prática filosófica é observada, conforme Pierre Hadot afirma em seu livro Philosophy as a Way of Life, de forma mais marcante, no período helenístico, com o surgimento de escolas filosóficas como o estoicismo, epicurismo, pirronismo etc. Sobre a filosofia naquele período, Hadot (1999, p.265) afirma que: "[...] was a mode of existing-in-the-world, which had to be practiced at each instant, and the goal of which was to transform the whole of the individual's life.”. E ele complementa: 
"The ancients knew that They would never be able to realize wisdom within themselves as a stable, definitive state, but they at least hoped to accede to it in certain privileged moments, and wisdom was the transcendent norm which guided their action." (HADOT, 1999, p.265)

Epicteto demarca o aspecto prático de sua filosofia em vários momentos de sua obra. Como aponta Long (2007, p.103): “[...] Epictetus treats philosophy as an enterprise that is very specifically addressed to individual persons from whom it demands a frank recognition of their present needs and inadequacies.". Para amparar a interpretação feita por Long, encontramos várias provas textuais em que Epicteto demarca a relação direta entre a sua filosofia e o modo de vida daquele que diz seguir o estoicismo. Em seu Manual, por exemplo, encontramos os seguintes trechos:

[7] Em uma viagem marítima, se saíres para fazer provisão de água quando o navio estiver ancorado, poderás também pegar uma conchinha e um peixinho pelo caminho. Mas é preciso que mantenhas o pensamento fixo sobre o navio, voltando-te continuamente. Que jamais o piloto te chame. E se te chamar, abandona tudo para que não sejas lançado ao navio amarrado como as ovelhas. Assim também é na vida. Não será um obstáculo se ela te der, ao invés de uma conchinha e um peixinho, uma mulherzinha e um filhinho. Mas se o capitão te chamar, corre para o navio, abandonando tudo, sem te voltares para trás. E se fores velho, nunca te afastes muito do navio, para que, um dia, quando o piloto te chamar, não fiques para trás. (EPICTETO, 2012, p.21)

[16] Quando vires alguém aflito, chorando pela ausência do filho ou pela perda de suas coisas, toma cuidado para que a representação de que ele esteja envolto em males externos não te arrebate, mas tem prontamente à mão que não é o acontecimento que o oprime (pois este não oprime outro), mas sim a opinião sobre $<_{0}$ acontecimento $>$. No entanto, não hesites em solidarizar-te com ele com tuas palavras e, caso caiba, em lamentar-te junto. Mas toma cuidado para também não gemeres por dentro. (EPICTETO, 2012, p.27)

Devemos entender que quando falamos em estoicismo e daoismo, estamos nos referindo a duas propostas de pensamento distintas que se colocam como opções para um modo de vida que se dirige a um estado particular de existência, que se realiza na figura do sábio. Sobre isso, Jiyuan Yu (2008, p.05) destaca que, apesar de definições distintas sobre o que seria a natureza do universo, tanto o estoicismo quanto o daoismo sustentam a crença de que o modo ideal de viver é aquele que está em acordo com a natureza universal.

Ao longo do Dao De Jing, podemos encontrar várias referências ao termo natureza ou naturalidade, ziran (自然). No capítulo 23, por exemplo, Laozi diz que "É 
natural falar pouco" e no capítulo 64 ele apresenta o seguinte trecho "Revertendo os vícios da multidão, sem intervir, ele [o sábio] favorece a naturalidade de todos os seres". Compreender o que representa ziran significa perceber a naturalidade das 10.000 coisas, a miríade de seres que são gerados pelo Dao, e implica em aceitar os fenômenos tais quais eles são. Isto é, para Laozi, ser sábio, ou tornar-se o shengren.

A definição do shengren daoista não parece estar tão longe do que a doutrina filosófica estoica apresenta. De acordo com John Sellars:

\begin{abstract}
"If we want to be happy, to live well, then we should cultivate virtue or excellence. What this means in practice is focusing our attention on the internal state of our souls rather than external objects that are out of our control. Although great riches and successful career might be nice, they will not bring us a fulfilled life if internally we are a chaotic jumble of confused opinions, violent emotions and contradictory beliefs. This ethical ideal proposed by the Stoics is famously presented as living in accordance with Nature. [...] Is living according with Nature, living in harmony with others one's own nature, or the nature of the cosmos as a whole? It is both [...]. In fact, it is possible to discern three aspects to this doctrine. The first is the idea of living harmoniously with oneself, that is, of living consistently and free from internal conflict. The second is living according to one's nature as a rational being and, in particular, of following this rather than passively reacting to external forces. The third is the idea of bringing oneself into harmony with Nature as a whole. As Nature as a whole is organized by the active principle that is God, and our own nature is but a part of this, there will be no conflict between living according to our own nature and living according to Nature as a whole." (SELLARS, 2006, p.125)
\end{abstract}

Assim como a relação com a natureza parece ser um ponto de aproximação entre o estoicismo e o daoismo, encontramos, também, semelhanças entre o modo de ação dos estoicos diante do que eles chamam de representação e a forma como os daoistas encaram os fenômenos do mundo. Se por naturalidade, no daoismo, entendemos que devemos compreender que uma coisa $\mathrm{X}$ é aquilo que é enquanto tal, então, podemos traçar um interessante paralelo com o estoicismo epictetiano e a sua relação com as representações. Logo no início do Manual de Epicteto é dito o seguinte: 
“[1.1] Das coisas existentes, algumas são encargos nossos; outras não. São encargos nossos o juízo, o impulso, o desejo, a repulsa - em suma: tudo quanto seja ação nossa. Não são encargos nossos o corpo, as posses, a reputação, os cargos públicos - em suma: tudo quanto não seja ação nossa. [1.2] Por natureza, as coisas que são encargos nossos são livres, desobstruídas, sem entraves. As que não são encargos nossos são débeis, escravas, obstruídas, de outrem. [...] [1.5] Então pratica dizer prontamente a toda representação bruta: "És uma representação e de modo algum a coisa que se apresenta". Em seguida, examina-a e testa-a com essas mesmas regras que possuis, em primeiro lugar e principalmente se é sobre coisas que são encargos nossos ou não. E caso esteja entre as coisas que não sejam encargos nossos, tem à mão que: "Nada é para mim"." (EPICTETO, 2012, p.15)

Como podemos perceber, a figura arquetípica do sábio, como modelo ideal a ser seguido pela humanidade, envolve, entre outros aspectos, uma nova atitude em relação à sua existência no mundo, a saber, o afastamento da subjetividade no julgamento dos fenômenos ou eventos que venham a surgir na vida daquele é considerado um sábio. Essa nova leitura de mundo, delineada pela resistência de se adicionar os julgamentos subjetivos a uma experiência específica, é um traço semelhante entre Epicteto e Laozi.

Outro elemento fundamental para a construção do modo de ação do sábio estoico e daoista está expresso em suas noções sobre os princípios responsáveis pela geração e organização do mundo. É aqui que a Natureza/Deus, para os estoicos, e o Dao (道), para os daoistas, com as suas similaridades e diferenças, se apresentam com mais um importante campo de discussão entre essas duas tradições de pensamento. Mas o que é a natureza para os chineses e gregos da Antiguidade? Jiyuan Yu nos diz o seguinte:

Ancient Chinese and Greek ethics generally appeals to human nature, although there are various notions of what human nature is. In advocating the ideal of living with nature, Stoicism and Daoism move one step further and ground their understandings of human nature in cosmic or universal nature. Both maintain that the nature of human beings is a part of nature at large. For Stoicism, "Our natures are parts of the nature of the universe."

For Daoism, "The dao is everywhere" and nothing escapes it, including human beings. Although it does not use much the term xin (human nature), Daoism holds a dao-de structure: de (power or virtue which gives each individual its character) is the manifestation of the general dao in that individual. Indeed, it is due to the kinship of human nature with the nature of the universe that living with nature is the best life. In this sense, to conform to nature does not mean to conform to an external standard. (JIYUAN YU, 2008, p.02)

De acordo com Jiyuan $\mathrm{Yu}$, podemos encontrar no estoicismo e no daoismo uma relação direta entre o princípio fundamental que gera, organiza e mantém o 
universo e a própria natureza humana. Epicteto e Laozi, portanto, se aproximam ao considerar a humanidade como parte integrante de uma estrutura maior, ou seja, somos partes integrantes de um cosmos.

O estudo da Natureza, para os gregos, é concebido a partir de sua teoria para

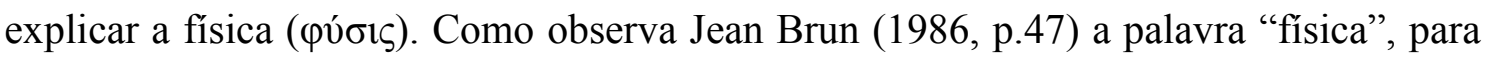
os gregos, tem significado diverso da forma como a compreendemos hoje. A física grega, desde os pré-socráticos, está relacionada com a palavra púcıv, que significa crescer, e representa o estudo da Natureza. Estudar a Natureza é, de acordo com Brun, examinar a própria vida e, por isso, o estudo $\varphi v ́ \sigma ı \varsigma$, é essencial para estoicos. Long (2007, p.118) ressalta que a física estoica, e epictetiana, envolve um campo extenso de temas que inclui a teologia e o estudo da natureza humana, dando ênfase ao estudo da alma e das faculdades mentais do homem.

Pierre Hadot (1999, p.193) e Long (2007, p.112) indicam que a obra de Epicteto divide-se em três campos: aquele que estuda os desejos e aversões e que, portanto, estão relacionados diretamente à natureza humana; o campo das inclinações, ou ações, que trata da relação dos homens entre si, ou seja, é aqui que se estrutura o estudo da ética, e o campo do assentimento, que envolve a nossa capacidade de julgar as representações, sendo, portanto, um campo da lógica. Tratando-se do primeiro campo, Hadot diz:

\footnotetext{
"The first area is that of desire and aversion. People are unhappy because they desire things they may either lose or fail to obtain, and because they try to avoid misfortunes which are often inevitable. This happens because such desiderata as wealth and health, for example, do not depend on us. The discipline of desire consequently consists in accustoming ourselves to the gradual renunciation of such desires and aversions, so that, in the end, we shall desire only that which does depend on us - moral virtue - and shall also avoid only that which depends on us - moral evil. We are to regard everything which does not depend on us as indifferent; that is to say, we must not make any difference between such things.
}

Rather, we must accept them all, willed as they are by universal nature. The discipline of desire concerns the passions or emotions (pathe) which we feel as a result of what happens to us. (HADOT, 1999, p.193)

Long (2007, p.114) afirma que, dentre os três campos de estudo propostos por Epicteto, o estudo da física é o mais importante. Isso se justifica porque, sendo a física a área responsável por lidar com a natureza humana, o estudo promovido por ela é que 
torna possível ouvir a voz da razão e essa é uma condição essencial para que se avance para o estudo dos outros campos. Nas palavras de Epicteto:

\begin{abstract}
"[3] Of these, the most important and most urgent is that which is concerned with the passions, for these arise in no other way than through our being frustrated in our desires and falling into what we want to avoid. This is what brings about disturbances, confusions, misfortunes, and calamities, and causes sorrow, lamentation, and envy, making people envious and jealous, with the result that we become incapable of listening to reason." (EPICTETO 2014, p.147)
\end{abstract}

No daoismo não encontramos uma divisão de temas semelhante ao estoicismo, entretanto, isso não quer dizer que não existam questões semelhantes abordadas no Dao De Jing. Nesse sentido, a compreensão da natureza do Dao envolve compreender a própria natureza humana, uma vez que o sábio é aquele que espelha suas ações no Dao. Laozi diz:

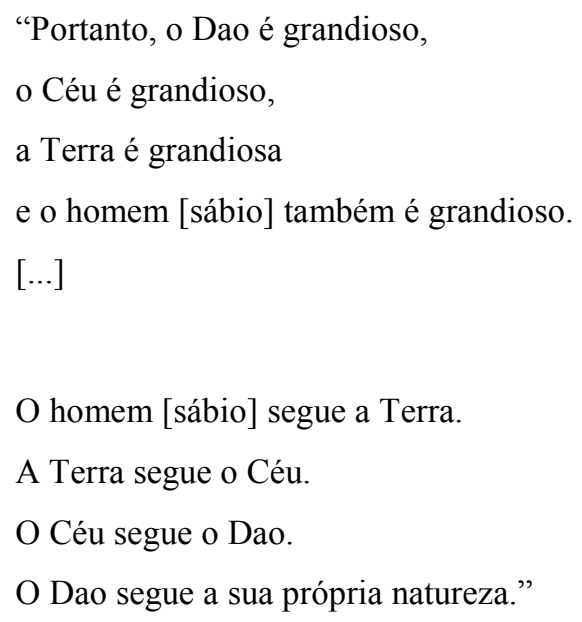

Nesse trecho fica claro que o sábio é aquele que segue a natureza do Dao, mas, que natureza é essa? Laozi responde a essa pergunta de várias maneiras ao longo do Dao De Jing, mas, podemos sintetizar essas respostas em dois termos que, no decorrer da obra, tornam-se sinônimos: naturalidade (ziran 自然) e não ação (wuwei 无为).

O Dao é ziran porque ele opera sendo aquilo que ele é, isto é, o Dao segue a sua natureza na espontaneidade, sem constrangimentos. Nesse sentido, Laozi compara o Dao com a imagem da água, pois a água beneficia todos os seres sem fazer distinção, isto é, ela banha todos os espaços e segue o seu fluxo naturalmente. O Dao também é wuwei uma vez que a não ação implica em agir sem se apegar ao resultado de seus atos. É por isso que Laozi diz que o sábio se retira uma vez cumprida a sua obra. Diante disso, 
entendemos que o sábio daoista é aquele que age em harmonia com as 10 mil coisas, isto é, ele atua sem constranger a natureza do universo que o circunda e, portanto, ele também não se deixa constranger porque atua ora avançando ora recuando tal qual a maré do oceano. Além disso, por atuar a partir do princípio da não ação, o sábio mantém um estado de perene tranquilidade, tal qual como o ideal estoico da $\alpha \pi \alpha ́ \theta \varepsilon \iota \alpha$, uma condição em que aquele que atinge atua diante dos eventos que se colocam diante dele com completa equanimidade, ou seja, sem ser perturbado por sensações de desejo ou aversão.

\section{Conclusão}

$\mathrm{Na}$ elaboração desse artigo tentamos apresentar alguns pontos de destaque referentes ao pensamento de Laozi expressos na obra Dao De Jing. Tentamos também abordar relações entre aspectos dessa obra com a proposta estoica de Epicteto na construção do modo de ação ideal representado pela figura do homem sábio estoico e o shengren chinês.

Estamos cientes de que esse artigo, e suas implicações, estão tratando do tema em questão ainda de modo introdutório. Entendemos que o estoicismo não representa um bloco monolítico de pensamento e compreendemos que, ao longo de sua história, seus representantes mais ilustres apresentaram divergências metodológicas $\mathrm{e}$ interpretativas de alguns de seus princípios basilares. Da mesma forma, o Dao De Jing é uma obra cuja principal característica é a abertura para uma leitura que permite variadas abordagens. No entanto, e a despeito dos desafios inerentes à leitura de Epicteto e Laozi, esperamos que que alguns dos pontos levantados aqui sirvam de inspiração para aqueles interessados na pesquisa dessas duas tradições de pensamento.

\section{Referências:}

BRUN, Jean. O Estoicismo. Lisboa. Edições 70, 1986.

CHAN, Wing-Tsit. A Sourcebook in Chinese Philosophy. Traduzido e compilado por Wing-Tsit Chan. Princeton. Princeton University Press, 1963.

CHANG, Chung-yuan. Tao: a new way of thinking. A translation of the Tao Tê Ching with a introduction and commentaries. London, Singing Dragon, 2014.

EPICTETO. As Diatribes de Epicteto, Livro I. Tradução: Aldo Dinucci. Coimbra, Imprensa da Universidade de Coimbra, 2020. 
EPICTETO. Discourses, Fragments, Handbook. Tradução: Robin Hard. New York, Oxford University Press, 2014.

EPICTETO. O Encheirídion de Epicteto. Edição Bilíngue. Tradução do texto grego e notas por Aldo Dinucci e Alfredo Julien. 1 a edição. São Cristovão. Universidade Federal de Sergipe, 2012.

HADOT, Pierre. Exercícios Espirituais e Filosofia Antiga. 2a impressão. São Paulo. É Realizações, 2014.

HADOT, Pierre. O que é a Filosofia Antiga. 6 edição. São Paulo. Edições Loyola, 2014.

HADOT, Pierre. Philosophy as a Way of Life. Oxford. Blackwell Publishers, 1999.

KHON, Livia. Introducing Daoism. London and New York. Routledge, 2009.

LAOZI, Dao De Jing: Escritura do Caminho e Escritura da Virtude com os comentários do Senhor às Margens do Rio / Laozi; tradução, notas, variantes e seleção de textos de Giorgio Sinedino. São Paulo: Editora Unesp, 2016.

LAOZI. Dao De Jing: O livro do Tao / Laozi; tradução de Chiu Yi Chih. São Paulo: Editora Mantra, 2017.

LAFARGUE, Michael. The Tao of the Tao Te Ching : a translation and commentary. Albany. State University of New York Press, 1992.

LONG, A.A. Epictetus. A Stoic and Socratic Guide to Life. New York. Oxford University Press, 2007.

SELLARS, John. Stoicism. Berkeley. University of California Press, 2006.

WONG, Eva. Taoism: an essential guide. Boston. Shambhala Publications, 1997.

YU, Jiyuan. Living with Nature: Stoicism and Daoism. History of Philosophy Quarterly, Vol. 25, No. 1 (Jan., 2008), pp. 1-19. 